\title{
BMJ Open Association of high birth weight with overweight and obesity in Chinese students aged 6-18 years: a national, cross-sectional study in China
}

Zhiyong Zou, Zhongping Yang, Zhaogeng Yang, Xijie Wang, Di Gao, Yanhui Dong, Jun Ma, Yinghua Ma

To cite: Zou Z, Yang Z, Yang Z, et al. Association of high birth weight with overweight and obesity in Chinese students aged $6-18$ years: a national, cross-sectional study in China. BMJ Open 2019;9:e024532. doi:10.1136/ bmjopen-2018-024532

\section{- Prepublication history and} additional material for this paper are available online. To view these files, please visit the journal online (http://dx.doi. org/10.1136/bmjopen-2018024532).

Received 31 May 2018 Revised 7 April 2019 Accepted 9 April 2019
Check for updates

(C) Author(s) (or their employer(s)) 2019. Re-use permitted under CC BY-NC. No commercial re-use. See rights and permissions. Published by BMJ.

Institute of Child and Adolescent Health, School of Public Health, Peking University, Beijing, China

Correspondence to

Professor Jun Ma; majunt@bjmu.edu.cn and Dr Yinghua Ma;

yinghuama@bjmu.edu.cn

\section{ABSTRACT}

Background The prevalence of childhood overweight and obesity in China has drastically increased 57 times over the past 30 years, and to control birth weight is an effective way to reduce the risk of overweight and obesity across the life course.

Objective This paper aimed to evaluate the association of high birth weight (HBW) with overweight and obesity in Chinese students aged $6-18$ years.

Methods All students with HBW $(n=4981)$ aged 6-18 years were selected from a cross-sectional survey from seven provinces of China, and 4981 other students with normal birth weight (NBW) were randomly sampled with matched gender, age and province. Anthropometric parameters were measured and characteristics were collected by questionnaires. Multiple logistic regression was used to estimate the OR of overweight and obesity with HBW, unadjusted and adjusted for confounding factors.

Results Participants with HBW revealed higher body mass index in childhood. The prevalence of overweight and obesity was significantly higher in the HBW group than in the NBW group (overweight $15.3 \%$ vs $13.1 \%$, $p<0.05$; obesity $16.9 \%$ vs $10.6 \%, p<0.05$ ), and the results were similar for overweight in all age groups except age 6-7, age 14-15 and age 16-18. Additionally, HBW was positively associated with overweight $(0 \mathrm{R}=1.230 ; 95 \% \mathrm{Cl}$ 1.056 to 1.432$)$ and obesity $(\mathrm{OR}=1.611 ; 95 \% \mathrm{Cl} 1.368$ to 1.897) after adjustment for covariates.

Conclusions HBW leads to an increased risk of overweight and obesity in childhood; thus, measures to control birth weight, such as controlling gestational weight gain, should be taken from the earliest beginning of life. Trial registration number NCT02343588; Post-results.

\section{INTRODUCTION}

Overweight and obesity in childhood have become a critical health issue with the continuous increase in prevalence worldwide, ${ }^{1}$ especially in China. ${ }^{2}{ }^{3}$ The prevalence of obesity in Chinese students aged 7-18 years has increased from $0.13 \%$ in 1985 to $7.26 \%$ in $2014,{ }^{4}$ while the prevalence of overweight increased from $6.3 \%$ in 1991 to $17.1 \%$ in
Strengths and limitations of this study

- This study used a national multicentred sample covering all-age children and adolescents in school.

- The 1:1 matching of gender, age and province between high birthweight group and normal birthweight group was used to enhance the study.

- Some maternal data, such as maternal age of pregnancy and gestational weight gain, were not collected in the survey, which may influence the results.

- $70.9 \%$ of birth weight was reported based on the health clinic card or birth certificate, with the other $29.1 \%$ recalled by their parents twice during 6 months, which may have recall bias.

2011. ${ }^{5}$ Overweight and obesity are considered high-risk factors for cardiovascular and metabolic complications, ${ }^{6-8}$ and students with overweight and obesity are more likely to suffer physical and psychosocial problems in adulthood. ${ }^{9-11}$ Previous studies have shown that an improvement in physical activity (PA) or dietary intake could produce stronger effects than those without it, while the number of health behaviours was inversely related to the intervention effects for obesity, ${ }^{12}{ }^{13}$ and the difficulty in preventing obesity is that obesity is the result of many factors, including genetics, unhealthy lifestyle, family environment as well as heavy marketing of unhealthy food products. ${ }^{13} 14$

The Developmental Origins of Health and Disease hypothesis postulates that adverse influence on intrauterine life can lead to permanent readjustments in physiology and metabolism, which further cause increased risk of diseases in later life. Thus, focusing on the early developmental phase of life offers a new way to understanding the mechanism of overweight and obesity. ${ }^{15}$ In childhood and puberty, the association between birth weight and obesity has been continually observed in 
cross-sectional, ${ }^{16}{ }^{17}$ longitudinal ${ }^{18}$ and cohort $^{19}$ studies. Most studies have found that high birth weight (HBW) was related to elevated risk of obesity in children or adolescents, ${ }^{16-19}$ and healthy lifestyle intervention before and during pregnancy could be effective in reducing the risk of HBW, which meant a balanced diet with low glycaemic load, light-intensity to moderate-intensity PA, and moderate weight gain during pregnancy. ${ }^{2021}$ However, very few studies have focused on Chinese school-age children, nor have they accounted for regional differences and provincial disparities; thus, a multicentred study is needed to clarify the associations.

Using baseline survey data from seven provinces in China, the present study aimed to evaluate the association of HBW with overweight and obesity among school children aged 6-18 years, and also to investigate the strength of association between HBW and body mass index (BMI) z-score.

\section{METHODS}

\section{Sample and participants}

Sampling was based on a cross-sectional baseline survey from seven provinces in China (Liaoning, Tianjin, Ningxia, Shanghai, Chongqing, Hunan and Guangdong) prior to the commencement of a national multicentred intervention trial, and these provinces covered all seven geographical areas of China. The protocol of the cluster, randomised controlled trial was previously published. ${ }^{22}$

Using the common criteria of HBW, ${ }^{16}{ }^{18}$ all students aged 6-18 years with birth weight over $4.0 \mathrm{~kg} \quad(\mathrm{n}=4981)$ were selected from a baseline survey of 65347 students, and 4981 other students with normal birth weight (NBW, $2.5 \mathrm{~kg} \leq$ birth weight $<4.0 \mathrm{~kg}$ ) were randomly sampled with matched age, gender and province. Finally, 9962 students, including 4981 students in the HBW group and 4981 students in the NBW group, were enrolled in the present study and were further divided into six subgroups, shown in table 1 and table 2: NBW normal weight group $(\mathrm{n}=3800)$, NBW overweight group $(\mathrm{n}=653)$, NBW obesity group ( $n=528)$, HBW normal weight group $(\mathrm{n}=3380)$, HBW overweight group $(\mathrm{n}=760)$ and HBW obesity group ( $\mathrm{n}=841)$, while overweight and obesity were defined using the cut-off references developed by the Working Group on Obesity in China. ${ }^{23}$

\section{Birthweight data}

Birth weight data were collected using a standard parent questionnaire. Parents were required to record their children's birth weight based on the birth certificate or health clinic record. If they did not have it, parents were asked to recall the birth weight based on their own measurements. About $70.9 \%$ of parents record the information of their children's birth weight based on the health clinic card or birth certificate, and the proportions in the HBW group and the NBW group were $73.4 \%(3655 / 4981)$ and $68.4 \%$ $(3406 / 4981)$, respectively. To ensure the reliability of birthweight data, parents were asked to repeat the same process of questionnaire survey 6 months later. The error in birthweight values between the baseline and 6 months later was lower than $10 \%$, and participants with an error over $10 \%$ were eliminated in this study.

\section{BMI and blood pressure}

Height and weight were measured by trained project members and experienced research nurses and doctors according to standardised procedure. To record these measurements, students were asked to stand straight in light clothing and without shoes. A portable stadiometer and a lever-type weight scale were validated and then used to measure height and weight, twice respectively. The mean value for both height and weight measurements was calculated using the duplicate measures. Height was measured to the nearest $0.1 \mathrm{~cm}$ and weight was measured to the nearest $0.1 \mathrm{~kg}$. In rechecking $5 \%$ of the students, the error was less than $3 \%$, or if higher all students were remeasured according to the protocol. BMI was calculated as body weight divided by height $(\mathrm{m})$ squared (kg/ $\left.\mathrm{m}^{2}\right)$.

Blood pressure was measured using a standardised mercury sphygmomanometer (model XJ1ID) recommended by the National High Blood Pressure Education Program (NHBPEP) Working Group in children and adolescents. The cuff size was selected according to the NHBPEP Working Group and placed approximately $2 \mathrm{~cm}$ above the crease of the elbow. The first reading was taken after students had sat at ease for at least $5 \mathrm{~min}$, with the students asked to keep quiet through the whole measurement. Systolic blood pressure (SBP) was determined by onset of the first Korotkoff sound and diastolic blood pressure (DBP) was defined by the fifth Korotkoff sound. This was performed twice, with the average recorded and used in this study. Elevated blood pressure in children and adolescents was defined as SBP or DBP or both higher than the corresponding cut-offs. The cut-offs were age-specific, gender-specific and height percentile-specific as recommended by the NHBPEP Working Group in $2004 .^{24}$

\section{Questionnaires}

The research team developed self-reported questionnaires for children and parents to collect information on obesity-related factors. Child-reported questionnaires were filled in by students in the classroom, with interpretation performed by trained research staff, with the exception of children at third grade or under primary school, who completed the questionnaires at home with guardians' assistance. Parent-reported questionnaires were all finished by students' guardians.

Child-reported questionnaires contained diet intake (fruit, vegetable and sugar-sweetened beverage), moderate PA, vigorous PA and sedentary time of students. For diet intake, students were asked how many days they eat fruits and vegetables or drink sugar-sweetened beverages, and how many servings or cups of these for each day in the past 7 days. The average intake was calculated: (days 
Table 1 Characteristics of study subjects with normal weight against overweight

\begin{tabular}{|c|c|c|c|c|c|}
\hline Baseline characteristics & $\begin{array}{l}\text { NBW normal group } \\
(3800)\end{array}$ & $\begin{array}{l}\text { NBW overweight } \\
\text { group (653) }\end{array}$ & $\begin{array}{l}\text { HBW normal } \\
\text { group (3380) }\end{array}$ & $\begin{array}{l}\text { HBW overweight } \\
\text { group }(760)\end{array}$ & $P$ value \\
\hline Male, n (\%) & $2190(57.6)$ & $441(67.5)$ & $1906(56.4)$ & $505(66.4)$ & $<0.001$ \\
\hline Age (year), mean $\pm S D$ & $11.16 \pm 0.05$ & $10.76 \pm 0.13$ & $11.29 \pm 0.06$ & $10.83 \pm 0.12$ & $<0.001$ \\
\hline Urban area, n (\%) & $2146(56.5)$ & $388(59.4)$ & $2144(63.4)$ & $501(65.9)$ & $<0.001$ \\
\hline Single child, n (\%) & $2488(65.5)$ & $479(73.4)$ & $1966(58.2)$ & $524(68.9)$ & $<0.001$ \\
\hline \multicolumn{6}{|l|}{ Birth information } \\
\hline Caesarean birth, n (\%) & $1330(37.4)$ & $269(43.7)$ & $1424(43.4)$ & $420(56.3)$ & $<0.001$ \\
\hline Single birth, $\mathrm{n}(\%)$ & $3488(97.0)$ & $604(98.1)$ & $3242(97.9)$ & 739 (98.9) & 0.001 \\
\hline Breast feeding, $\mathrm{n}(\%)$ & $3098(86.0)$ & $536(86.3)$ & $2887(86.9)$ & $636(85.1)$ & 0.552 \\
\hline \multicolumn{6}{|l|}{ Anthropometry, mean $\pm S D$} \\
\hline Height (cm) & $146.08 \pm 17.36$ & $147.24 \pm 16.49$ & $148.44 \pm 17.30$ & $149.16 \pm 16.92$ & $<0.001$ \\
\hline Diastolic pressure $(\mathrm{mm} \mathrm{Hg})$ & $65.71 \pm 8.29$ & $67.93 \pm 8.99$ & $65.78 \pm 8.28$ & $67.04 \pm 8.55$ & $<0.001$ \\
\hline Body mass index $\left(\mathrm{kg} / \mathrm{m}^{2}\right)$ & $17.26 \pm 2.39$ & $21.47 \pm 2.74$ & $17.61 \pm 2.32$ & $21.58 \pm 2.71$ & $<0.001$ \\
\hline \multicolumn{6}{|l|}{ Diet and physical activity, mean \pm SD } \\
\hline Fruit (serving/day) & $1.20 \pm 1.03$ & $1.25 \pm 0.96$ & $1.27 \pm 1.08$ & $1.20 \pm 0.95$ & 0.050 \\
\hline Vegetable (serving/day) & $1.77 \pm 1.40$ & $1.79 \pm 1.42$ & $1.78 \pm 1.43$ & $1.78 \pm 1.43$ & 0.976 \\
\hline Sugar-sweetened beverage (cup/day) & $0.42 \pm 0.75$ & $0.49 \pm 0.92$ & $0.45 \pm 0.80$ & $0.46 \pm 0.86$ & 0.167 \\
\hline Moderate PA (hour/day) & $0.49 \pm 0.81$ & $0.46 \pm 0.72$ & $0.52 \pm 0.82$ & $0.50 \pm 0.89$ & 0.196 \\
\hline Vigorous PA (hour/day) & $0.47 \pm 0.78$ & $0.46 \pm 0.65$ & $0.47 \pm 0.74$ & $0.49 \pm 0.82$ & 0.850 \\
\hline Sedentary time (hour/day) & $5.73 \pm 3.76$ & $5.75 \pm 3.58$ & $5.87 \pm 3.73$ & $5.72 \pm 3.76$ & 0.442 \\
\hline None/Primary & $369(10.4)$ & $57(9.3)$ & 407 (12.4) & $73(9.9)$ & $<0.001$ \\
\hline Secondary & $2417(67.9)$ & $392(63.5)$ & $2181(66.3)$ & $467(63.3)$ & \\
\hline College and above & $772(21.7)$ & $168(27.2)$ & $702(21.3)$ & $198(26.8)$ & \\
\hline \multicolumn{6}{|l|}{ Family history, n (\%) } \\
\hline Paternal hypertension & $144(4.1)$ & $27(4.5)$ & $128(4.0)$ & $37(5.1)$ & 0.558 \\
\hline Maternal hypertension & $66(1.9)$ & $17(2.8)$ & $95(3.0)$ & $25(3.5)$ & 0.014 \\
\hline Paternal diabetes & $41(1.2)$ & $11(1.9)$ & $39(1.2)$ & $14(2.0)$ & 0.251 \\
\hline Maternal diabetes & $17(0.5)$ & $4(0.7)$ & $31(1.0)$ & $11(1.6)$ & 0.017 \\
\hline Paternal obesity & $176(5.3)$ & $49(8.5)$ & $159(5.1)$ & $59(8.6)$ & $<0.001$ \\
\hline Maternal obesity & 108 (3.2) & $19(3.3)$ & $128(4.1)$ & $42(6.1)$ & 0.003 \\
\hline
\end{tabular}

HBW, high birth weight; NBW, normal birth weight; PA, physical activity; WC, waist circumference.

$\times$ servings/cups for each day) $/ 7$. One serving of fruits or vegetables was defined as the size of an adult's fist, while one cup of sugar-sweetened beverage was defined as almost $250 \mathrm{~mL}$. Data on moderate and vigorous PA (MVPA) were collected by asking how many days students do moderate or vigorous PA and how many hours for each day over the past 7 days. The average PA followed the calculation of (days $\times$ hours for each day) $/ 7$. Moderate PA included light activities (eg, walking), while vigorous PA included high-load activities on musculoskeletal tissues of the body (eg, sports and games).$^{25}$ For sedentary time, consisting of doing homework, watching television and using a computer, students were asked how many days and how many hours were spent on the three separate activities over the past 7 days. Following the calculation of (days $\times$ hours for each day) $/ 7$ for each activity, the average sedentary time was the sum of homework, television and computer time. 
Table 2 Characteristics of study subjects with normal weight against obesity

\begin{tabular}{|c|c|c|c|c|c|}
\hline Baseline characteristics & $\begin{array}{l}\text { NBW normal } \\
\text { group (3800) }\end{array}$ & $\begin{array}{l}\text { NBW obesity } \\
\text { group (528) }\end{array}$ & $\begin{array}{l}\text { HBW normal } \\
\text { group (3380) }\end{array}$ & $\begin{array}{l}\text { HBW obesity } \\
\text { group (841) }\end{array}$ & $P$ value \\
\hline Male, $n(\%)$ & $2190(57.6)$ & $383(72.5)$ & $1906(56.4)$ & $603(71.7)$ & $<0.001$ \\
\hline Age (year), mean $\pm S D$ & $11.16 \pm 0.05$ & $10.14 \pm 0.13$ & $11.29 \pm 0.06$ & $10.23 \pm 0.11$ & $<0.001$ \\
\hline Urban area, n (\%) & $2146(56.5)$ & $315(59.7)$ & $2144(63.4)$ & $564(67.1)$ & $<0.001$ \\
\hline Single child, $\mathrm{n}(\%)$ & $2488(65.5)$ & $410(77.7)$ & $1966(58.2)$ & 605 (71.9) & $<0.001$ \\
\hline \multicolumn{6}{|l|}{ Birth information } \\
\hline Birth weight $(\mathrm{kg})$, mean $\pm \mathrm{SD}$ & $3.22 \pm 0.35$ & $3.31 \pm 0.35$ & $4.21 \pm 0.29$ & $4.24 \pm 0.32$ & $<0.001$ \\
\hline Caesarean birth, $\mathrm{n}(\%)$ & $1330(37.4)$ & $256(50.2)$ & $1424(43.4)$ & $534(64.3)$ & $<0.001$ \\
\hline Single birth, $\mathrm{n}(\%)$ & $3488(97.0)$ & $502(97.1)$ & $3242(97.9)$ & $811(98.2)$ & 0.511 \\
\hline Breast feeding, $\mathrm{n}(\%)$ & $3098(86.0)$ & $413(79.7)$ & $2887(86.9)$ & $721(86.7)$ & 0.017 \\
\hline \multicolumn{6}{|l|}{ Anthropometry, mean $\pm S D$} \\
\hline Height (cm) & $146.08 \pm 17.36$ & $146.62 \pm 15.50$ & $148.44 \pm 17.30$ & $148.69 \pm 15.87$ & $<0.001$ \\
\hline Weight (kg) & $38.18 \pm 13.00$ & $55.83 \pm 19.37$ & $40.11 \pm 13.13$ & $58.75 \pm 20.96$ & $<0.001$ \\
\hline WC (cm) & $61.64 \pm 8.09$ & $80.27 \pm 11.25$ & $62.70 \pm 7.83$ & $81.67 \pm 11.63$ & $<0.001$ \\
\hline Systolic pressure $(\mathrm{mm} \mathrm{Hg})$ & $103.88 \pm 11.51$ & $111.92 \pm 13.43$ & $103.98 \pm 11.36$ & $111.24 \pm 13.10$ & $<0.001$ \\
\hline Diastolic pressure $(\mathrm{mm} \mathrm{Hg})$ & $65.71 \pm 8.29$ & $70.43 \pm 9.59$ & $65.78 \pm 8.28$ & $70.15 \pm 8.78$ & $<0.001$ \\
\hline Body mass index $\left(\mathrm{kg} / \mathrm{m}^{2}\right)$ & $17.26 \pm 2.39$ & $25.09 \pm 3.94$ & $17.61 \pm 2.32$ & $25.62 \pm 4.26$ & $<0.001$ \\
\hline \multicolumn{6}{|c|}{ Diet and physical activity, mean \pm SD } \\
\hline Fruit (serving/day) & $1.20 \pm 1.03$ & $1.32 \pm 1.03$ & $1.27 \pm 1.08$ & $1.36 \pm 1.09$ & $<0.001$ \\
\hline Vegetable (serving/day) & $1.77 \pm 1.40$ & $1.90 \pm 1.57$ & $1.78 \pm 1.43$ & $1.95 \pm 1.49$ & 0.003 \\
\hline $\begin{array}{l}\text { Sugar-sweetened beverage } \\
\text { (cup/day) }\end{array}$ & $0.42 \pm 0.75$ & $0.37 \pm 0.59$ & $0.45 \pm 0.80$ & $0.40 \pm 0.61$ & 0.041 \\
\hline Moderate PA (hour/day) & $0.49 \pm 0.81$ & $0.51 \pm 0.82$ & $0.52 \pm 0.82$ & $0.50 \pm 0.69$ & 0.375 \\
\hline Vigorous PA (hour/day) & $0.47 \pm 0.78$ & $0.48 \pm 0.45$ & $0.47 \pm 0.74$ & $0.47 \pm 0.67$ & 0.967 \\
\hline Sedentary time (hour/day) & $5.73 \pm 3.76$ & $5.87 \pm 3.75$ & $5.87 \pm 3.73$ & $5.74 \pm 3.56$ & 0.431 \\
\hline \multicolumn{6}{|l|}{ Socioeconomic status, n (\%) } \\
\hline Paternal education level & & & & & $<0.001$ \\
\hline None/Primary & $313(8.2)$ & $29(5.7)$ & $313(9.5)$ & $35(4.3)$ & \\
\hline Secondary & 2407 (67.3) & $319(62.5)$ & $2207(67.0)$ & 504 (61.5) & \\
\hline College and above & $876(24.5)$ & $162(31.8)$ & $776(23.5)$ & $281(34.2)$ & \\
\hline \multicolumn{6}{|l|}{ Maternal education level } \\
\hline None/Primary & $369(10.4)$ & $31(6.1)$ & $407(12.4)$ & $60(7.3)$ & $<0.001$ \\
\hline Secondary & 2417 (67.9) & $346(67.9)$ & $2181(66.3)$ & $529(64.0)$ & \\
\hline College and above & $772(21.7)$ & $168(26.0)$ & $702(21.3)$ & $198(28.7)$ & \\
\hline \multicolumn{6}{|l|}{ Family history, n (\%) } \\
\hline Paternal hypertension & $144(4.1)$ & $29(5.8)$ & $128(4.0)$ & $49(6.0)$ & 0.002 \\
\hline Maternal hypertension & $66(1.9)$ & $12(2.4)$ & $95(3.0)$ & $31(3.8)$ & 0.067 \\
\hline Paternal diabetes & $41(1.2)$ & $9(1.8)$ & $39(1.2)$ & $16(2.1)$ & 0.032 \\
\hline Maternal diabetes & $17(0.5)$ & $6(1.2)$ & $31(1.0)$ & $20(2.6)$ & $<0.001$ \\
\hline Paternal obesity & $176(5.3)$ & $59(12.4)$ & $159(5.1)$ & $88(11.5)$ & $<0.001$ \\
\hline Maternal obesity & 108 (3.2) & $25(5.3)$ & $128(4.1)$ & $65(8.5)$ & $<0.001$ \\
\hline
\end{tabular}

HBW, high birth weight; NBW, normal birth weight; PA, physical activity; WC, waist circumference.

The parent-reported questionnaire collected the child's birth information (delivery, single birth or not, and breast feeding), single child or not, socioeconomic status (parents' education levels) and family history (hypertension, diabetes and obesity). Delivery mode included spontaneous delivery and caesarean delivery. Breast feeding 
was categorised as $\geq 6$ months and $<6$ months. Socioeconomic status was defined as education levels of children's parents, involving three levels: primary school or below, secondary school, and college or above. In this study, family history covered father's and mother's history of hypertension, diabetes and obesity. This was established through a diagnosis of hypertension or diabetes according to their medical history, while BMI was calculated by weight $/$ height $^{2}\left(\mathrm{~kg} / \mathrm{m}^{2}\right)$ for height and weight values provided in the questionnaire. Adult obesity was defined as BMI $\geq 28 \mathrm{~kg} / \mathrm{m}^{2}$ in the Chinese guideline for adult obesity. ${ }^{26}$

\section{Patient and public involvement}

Students and their parents were not involved in setting the research question or outcome measures, nor were they involved in the recruitment and conduct of the study. School doctors and class teachers helped us to organise and maintain order of the physical examination by class held in the school.

\section{Statistical analyses}

EpiData Software V.3.02 was used for data entry, and all analyses were performed using IBM SPSS Statistics V.22.0. Age, birth weight, height, weight, BMI, DBP, SBP, sweet drinks and MVPA were recorded as mean value (SD). Gender, delivery, single birth, breast feeding, elevated blood pressure, parental education and family history were displayed as categorical variables (number and percentage). t-Test was conducted for the $\mathrm{p}$ value of BMI between the HBW group and the normal group by gender and age group, and $\chi^{2}$ test was verified for the percentage of overweight and obesity. Multivariate logistic regression was used to calculate the OR and 95\% CI of different birthweight groups for overweight and obesity by age group. This was further adjusted for urban-rural area, single child, delivery, food intake and PA, sedentary time, and elevated blood pressure in model 2 , and adjusted for paternal and maternal education level, and family history such as hypertension, diabetes and obesity in model 3. Sensitivity analyses were conducted with different thresholds for HBW compared with NBW, which are displayed in online supplementary table 1 . The criterion for statistical significance was $p$ value $<0.05$.

\section{RESULTS}

A total of 9962 children and adolescents aged 6-18 years were recruited in this study, and the distribution of characteristics in all groups is presented separately in table 1 and table 2. As presented in table 1, the mean value of birth weight was $3.22 \pm 0.35 \mathrm{~kg}, 3.25 \pm 0.36 \mathrm{~kg}, 4.21 \pm 0.29 \mathrm{~kg}$ and $4.21 \pm 0.26 \mathrm{~kg}$, respectively, for NBW normal weight group, NBW overweight group, HBW normal group and HBW overweight group. Compared with the other three groups, students in the HBW overweight group were observed with significantly higher rate of caesarean birth, urban area, single child, single birth, maternal hypertension, diabetes, obesity and parental obesity $(\mathrm{p}<0.05)$. The results in table 2 were similar between the HBW obesity group and the other three groups, except for the rate of parental hypertension and parental diabetes, which was significantly higher $(\mathrm{p}<0.05)$.

The associations between BMI z-score and birth weight in different age groups are shown in table 3 . All age groups were observed with significantly positive associations between BMI z-score and birth weight, the highest being in the 8-9 age group. When adjusted for urban-rural area, single child, fruit and vegetable intake, sugar-sweetened beverage, MVPA, sedentary time, and elevated blood pressure in model 2, the associations remained significant overall as well as in different age groups.

Table 4 presents the rate and OR for overweight and obesity on current weight by age groups. Overall, the HBW group revealed a significantly higher rate of

Table 3 Association between BMI z-score and birth weight in different age groups

\begin{tabular}{|c|c|c|c|c|c|c|}
\hline & \multicolumn{3}{|l|}{ Model 1* } & \multicolumn{3}{|l|}{ Model 2† } \\
\hline & $\begin{array}{l}\text { Standardised } \\
\text { coefficients }\end{array}$ & $95 \% \mathrm{Cl}$ & $P$ value & $\begin{array}{l}\text { Standardised } \\
\text { coefficients }\end{array}$ & $95 \% \mathrm{Cl}$ & $P$ value \\
\hline Birth weight & 0.117 & 0.100 to 0.133 & $<0.001$ & 0.100 & 0.079 to 0.120 & $<0.001$ \\
\hline Age 6-7 & 0.121 & 0.082 to 0.160 & $<0.001$ & 0.145 & 0.091 to 0.198 & $<0.001$ \\
\hline Age 8-9 & 0.162 & 0.126 to 0.197 & $<0.001$ & 0.161 & 0.116 to 0.205 & $<0.001$ \\
\hline Age $10-11$ & 0.134 & 0.090 to 0.179 & $<0.001$ & 0.103 & 0.048 to 0.158 & $<0.001$ \\
\hline Age $12-13$ & 0.098 & 0.061 to 0.135 & $<0.001$ & 0.091 & 0.044 to 0.139 & $<0.001$ \\
\hline Age 14-15 & 0.090 & 0.045 to 0.134 & $<0.001$ & 0.102 & 0.043 to 0.161 & 0.001 \\
\hline Age $16-18$ & 0.079 & 0.032 to 0.126 & 0.001 & 0.076 & 0.016 to 0.136 & 0.013 \\
\hline
\end{tabular}

General linear regression model was used to calculate the association between BMI z-score (dependent variable) and birth weight (independent variable).

*Model 1 was unadjusted for any covariates.

†Model 2 was adjusted for urban-rural area, single child, delivery, fruit and vegetable intake, sugar-sweetened beverage, moderate and vigorous physical activity, sedentary time, and elevated blood pressure.

BMI, body mass index. 
Table 4 OR of HBW group for overweight and obesity in different age groups

\begin{tabular}{|c|c|c|c|c|c|c|c|c|}
\hline & \multirow{2}{*}{$\begin{array}{l}\text { HBW group } \\
(\mathrm{n}=4981) \\
\mathrm{n}(\%)\end{array}$} & \multirow{2}{*}{$\begin{array}{l}\text { NBW } \\
\text { group } \\
(n=4981)\end{array}$} & \multicolumn{2}{|c|}{ Model 1† } & \multicolumn{2}{|c|}{ Model 2‡ } & \multicolumn{2}{|c|}{ Model 3§ } \\
\hline & & & ORt & $95 \% \mathrm{Cl}$ & AOR‡ & $95 \% \mathrm{Cl}$ & AOR§ & $95 \% \mathrm{Cl}$ \\
\hline Overweight & $760(15.3)^{*}$ & 653 (13.1) & $1.308^{*}$ & 1.167 to 1.467 & $1.242^{*}$ & 1.077 to 1.433 & $1.230^{*}$ & 1.056 to 1.432 \\
\hline Age 6-7 & $138(15.8)$ & 132 (15.2) & 1.155 & 0.887 to 1.505 & 1.163 & 0.806 to 1.677 & 1.244 & 0.847 to 1.828 \\
\hline Age 8-9 & $177(15.4)^{*}$ & 148 (12.9) & $1.422^{*}$ & 1.118 to 1.808 & $1.492^{*}$ & 1.111 to 2.005 & $1.508^{*}$ & 1.102 to 2.062 \\
\hline Age $10-11$ & $116(18.2)^{\star}$ & $88(13.8)$ & $1.566^{\star}$ & 1.151 to 2.132 & 1.441 & 0.978 to 2.124 & 1.354 & 0.895 to 2.049 \\
\hline Age 12-13 & $160(15.7)^{\star}$ & $135(13.3)$ & $1.318^{*}$ & 1.026 to 1.693 & 1.123 & 0.823 to 1.534 & 1.043 & 0.739 to 1.471 \\
\hline Age $14-15$ & $80(12.3)$ & $68(10.4)$ & 1.269 & 0.899 to 1.793 & 1.139 & 0.726 to 1.787 & 1.292 & 0.788 to 2.118 \\
\hline Age $16-18$ & 89 (13.5) & 82 (12.5) & 1.160 & 0.839 to 1.604 & 1.155 & 0.779 to 1.711 & 1.078 & 0.700 to 1.659 \\
\hline Obesity & 841 (16.9) & 528 (10.6) & $1.791^{*}$ & 1.591 to 2.016 & $1.673^{*}$ & 1.436 to 1.949 & $1.611^{*}$ & 1.368 to 1.897 \\
\hline Age 6-7 & $162(18.6)^{\star}$ & 108 (12.4) & $1.658^{*}$ & 1.276 to 2.168 & $1.692^{*}$ & 1.158 to 2.470 & $1.741^{*}$ & 1.167 to 2.596 \\
\hline Age 8-9 & $266(23.2)^{\star}$ & $162(14.1)$ & $1.952^{*}$ & 1.567 to 2.431 & $1.954^{*}$ & 1.456 to 2.622 & $1.844^{*}$ & 1.343 to 2.531 \\
\hline Age $10-11$ & $134(21.0)^{*}$ & 89 (13.9) & $1.789^{*}$ & 1.325 to 2.415 & $1.867^{\star}$ & 1.270 to 2.744 & $1.813^{*}$ & 1.203 to 2.730 \\
\hline Age $12-13$ & $141(13.9)^{*}$ & $86(8.5)$ & $1.823^{*}$ & 1.369 to 2.428 & $1.628^{*}$ & 1.116 to 2.373 & $1.641^{*}$ & 1.078 to 2.496 \\
\hline Age $14-15$ & $65(10.0)^{*}$ & $37(5.7)$ & $1.896^{*}$ & 1.244 to 2.889 & $1.837^{*}$ & 1.070 to 3.153 & $1.986^{*}$ & 1.097 to 3.597 \\
\hline Age $16-18$ & $73(11.1)^{\star}$ & $46(7.0)$ & $1.696^{*}$ & 1.150 to 2.502 & 1.546 & 0.922 to 2.593 & 1.256 & 0.705 to 2.238 \\
\hline
\end{tabular}

ORs of the HBW group for overweight and obesity were assessed by multivariate logistic regression with the dependent variable (overweight or obesity) and independent variable (birth weight).

${ }^{*} \mathrm{P}<0.05$.

†Model 1 was unadjusted for any covariates.

$\ddagger$ Adjusted for urban-rural area, single child, delivery, fruit and vegetable intake, sugar-sweetened beverage, moderate and vigorous physical activity, sedentary time, and elevated blood pressure.

$\S$ Further adjusted for paternal and maternal education level, hypertension, diabetes and obesity.

AOR, adjusted OR; HBW, high birth weight; NBW, normal birth weight.

overweight and obesity than those in the NBW group, and the OR was 1.308 (95\% CI 1.167 to 1.467) and 1.791 (95\% CI 1.591 to 2.016), respectively. After adjusting for confounding factors in models 2 and 3, slightly decreased but still significant associations were observed with an adjusted OR (AOR) of 1.230 (95\% CI 1.056 to 1.432 ) for overweight and 1.611 (95\% CI 1.368 to 1.897 ) for obesity. In different age groups, the results were similar, and AOR in the 8-9 age group for overweight and in most age groups for obesity remained significant. The results were similar in sensitivity analyses with different thresholds for HBW, which are displayed in online supplementary table 1.

\section{DISCUSSION}

We evaluated the associations of HBW and overweight and obesity using cross-sectional survey from seven provinces in China. In the present study, HBW was significantly associated with an increased risk of overweight and obesity among Chinese children and adolescents before and after adjusting for the covariables. More specifically, we found the 8-9 age group with HBW had the highest adjusted risk of 1.508 for overweight, and all age groups except age 16-18 with HBW had a higher risk for obesity.
Birth weight is commonly regarded as an important indicator for depicting development status in intrauterine environments. A meta-analysis gathering 643902 persons from 66 studies, aged 1-75, has proved that low birth weight and HBW were followed by opposite longterm effects on overweight compared with NBW, with HBW predisposed to overweight in later life with an OR of 1.66 (95\% CI 1.55 to 1.77$).{ }^{27}$ Many studies have also verified high level of birth weight as one strong predictor of obesity among children or adolescents. ${ }^{25} 26$ However, most studies in China, to our knowledge, were limited to one specific age group or one provincial area, which cannot reveal the overall association among children and adolescents more broadly. In this study, a significantly positive association between HBW and overweight and obesity was concluded, which is consistent with the results of previous studies. ${ }^{27-29}$ There are some possible explanations for the association. One possible explanation is that hypernutrition in pregnancy led to the increase of lean body mass or fat mass in the fetus, which might play an important role in obesity. ${ }^{30}{ }^{31}$ Another explanation is that birth weight might modify the genetic predisposition and thus affect the risk of obesity later in life. ${ }^{32}{ }^{33}$ Even though underlying mechanisms have been raised, there is no systematic explanation for birth weight and obesity. How 
birth weight affects obesity is a complex process within the life course and warrants further study.

Weight management during pregnancy was reported to be an effective way to control birth weight, ${ }^{20}{ }^{21} 34$ and evidence had proved that excessive gestational weight gain may lead to HBW and large-for-gestational age infants. ${ }^{35} 36$ The Institute of Medicine in the USA revised the gestational weight gain guidelines in 2009, encouraging health professionals and mothers to manage weight gain by following healthy dietary recommendations and increasing $\mathrm{PA}^{36}{ }^{36}$ and noted phone-based interventions can help pregnant women control gestational weight gain by providing guidance, reminders and educational materials. ${ }^{37}$ Other factors such as sedentary time might also influence the risk of obesity in children and adolescents. ${ }^{15}$ Some studies focused on the interactions of birth weight and diet and behavioural factors, ${ }^{27} 28$ and Ren $e t$ $a l^{29}$ also found the synergy effects of HBW and unhealthy diet on increased risk of obesity. Thus diet intervention studies on children with HBW are needed in the future.

There are three limitations to this study. First, data on birth weight were retrospectively obtained from their parents using a questionnaire. In this way, there was a possibility of memory bias. However, we have tried to weaken the bias by collecting information on their certificate or the health clinic card, then repeating the survey after 6 months. Subjects with a difference in birth weight of over $10 \%$ in the two investigations were excluded from the study. Second, using dietary recall over the last 7 days may be a less accurate method for daily intake of fruits and vegetables and sugar-sweetened beverage consumption, which may also influence the results. Third, some maternal confounders were not adjusted in the study because those factors were not collected in the survey, such as maternal age of pregnancy and gestational weight gain, which may also influence the results.

\section{CONCLUSION}

This study explored the association of HBW with overweight and obesity among students aged $6-18$ years based on a national cross-sectional survey in China. The results showed that HBW was positively associated with overweight and obesity in children. Most younger age groups with HBW were found to have a higher risk of overweight and obesity in childhood, with birth weight remaining positively associated with higher BMI z-score even after the adjustment. This study indicated that HBW is a highrisk factor for overweight and obesity in children, and thus measures to control birth weight, such as controlling gestational weight gain, should be taken as they may play an important role in the prevention and control of childhood overweight and obesity.

Acknowledgements The authors gratefully acknowledge all the team members and the participating students, school doctors, class teachers, parents, and local education and health staff of this project, and also acknowledge Christianne O'Donnell for language editing.
Contributors JM, YM and ZZ conceived and designed the project. ZZ collected the data. ZZ and ZPY analysed the data and prepared the manuscript. ZGY, XW, DG and $Y D$ were involved in writing the article and had the final approval of the submitted and published versions.

Funding This study was funded by the research special fund for public welfare industry of health of the Ministry of Health of China (№ 201202010) and the National Natural Science Foundation of China (№ 81773454) and China Scholarship Council (No 201806015008).

Competing interests None declared.

Patient consent for publication Obtained.

Ethics approval This study was approved by the Medical Ethical Committee of the Peking University (IRB00001052-13034), and written informed consent was given by all students and their guardians before the baseline survey commenced.

Provenance and peer review Not commissioned; externally peer reviewed. Data sharing statement No additional data are available.

Open access This is an open access article distributed in accordance with the Creative Commons Attribution Non Commercial (CC BY-NC 4.0) license, which permits others to distribute, remix, adapt, build upon this work non-commercially, and license their derivative works on different terms, provided the original work is properly cited, appropriate credit is given, any changes made indicated, and the use is non-commercial. See: http://creativecommons.org/licenses/by-nc/4.0/.

\section{REFERENCES}

1. $\mathrm{Ng} \mathrm{M}$, Fleming $\mathrm{T}$, Robinson $\mathrm{M}$, et al. Global, regional, and national prevalence of overweight and obesity in children and adults during 1980-2013: a systematic analysis for the Global Burden of Disease Study 2013. Lancet 2014;384:766-81.

2. Ji CY. Working Group on Obesity in China (WGOC). Report on childhood obesity in China (4) prevalence and trends of overweight and obesity in Chinese urban school-age children and adolescents, 1985-2000. Biomed Environ Sci 2007;20:1-10.

3. Song Y, Wang HJ, Ma J, et al. Secular trends of obesity prevalence in urban Chinese children from 1985 to 2010: gender disparity. PLoS One 2013;8:e53069.

4. Wang S, Dong $\mathrm{YH}$, Wang ZH, et al. [Trends in overweight and obesity among Chinese children of 7-18 years old during 1985-2014]. Zhonghua Yu Fang Yi Xue Za Zhi 2017;51:300-5.

5. Gordon-Larsen P, Wang H, Popkin BM. Overweight dynamics in Chinese children and adults. Obes Rev 2014;15 Suppl 1(Suppl 1):37-48.

6. Dong B, Wang Z, Song Y, et al. Understanding trends in blood pressure and their associations with body mass index in Chinese children, from 1985 to 2010: a cross-sectional observational study. BMJ Open 2015;5:e009050.

7. Dong B, Ma J, Wang HJ, et al. The association of overweight and obesity with blood pressure among Chinese children and adolescents. Biomed Environ Sci 2013;26:437-44.

8. Morandi A, Maffeis C. Predictors of metabolic risk in childhood obesity. Horm Res Paediatr 2014;82:3-11.

9. Kelsey MM, Zaepfel A, Bjornstad P, et al. Age-related consequences of childhood obesity. Gerontology 2014;60:222-8.

10. Llewellyn A, Simmonds M, Owen CG, et al. Childhood obesity as a predictor of morbidity in adulthood: a systematic review and metaanalysis. Obes Rev 2016;17:56-67.

11. Lauby-Secretan B, Scoccianti C, Loomis D, et al. International agency for research on cancer handbook working group: Body fatness and cancer-viewpoint of the IARC working group. $N$ Engl $J$ Med 2016;375:794-8.

12. $\mathrm{Li} \mathrm{XH}$, Lin S, Guo H, et al. Effectiveness of a school-based physical activity intervention on obesity in school children: a nonrandomized controlled trial. BMC Public Health 2014;14:1282.

13. Stice $E$, Shaw $H$, Marti $C N$. A meta-analytic review of obesity prevention programs for children and adolescents: the skinny on interventions that work. Psychol Bull 2006;132:667-91.

14. Pettigrew S, Borys JM, du Plessis HR, et al. Process evaluation outcomes from a global child obesity prevention intervention. BMC Public Health 2014;14:757.

15. Barker DJ. The origins of the developmental origins theory. J Intern Med 2007;261:412-7.

16. Yuan ZP, Yang M, Liang L, et al. Possible role of birth weight on general and central obesity in Chinese children and adolescents: a cross-sectional study. Ann Epidemiol 2015;25:748-52. 
17. Sacco MR, de Castro NP, Euclydes VL, et al. Birth weight, rapid weight gain in infancy and markers of overweight and obesity in childhood. Eur J Clin Nutr 2013;67:1147-53.

18. Loaiza S, Atalah E. Birth weight and obesity risk at first grade of high school in a non-concurrent cohort of Chilean children. Public Health Nutr 2013;16:228-32.

19. Zhang X, Liu E, Tian Z, et al. High birth weight and overweight or obesity among Chinese children 3-6 years old. Prev Med 2009;49(23):172-8.

20. Farpour-Lambert NJ, Ells LJ, Martinez de Tejada B, et al. Obesity and Weight Gain in Pregnancy and Postpartum: an Evidence Review of Lifestyle Interventions to Inform Maternal and Child Health Policies. Front Endocrinol 2018;9:546.

21. Kiani Asiabar A, Amin Shokravi F, Hajifaraji M, et al. The effect of an educational intervention in early pregnancy with spouse's participation on optimal gestational weight gain in pregnancy: a randomized controlled trial. Health Educ Res 2018;33:535-47.

22. Chen $Y, M a L, M a ~ Y$, et al. A national school-based health lifestyles interventions among Chinese children and adolescents against obesity: rationale, design and methodology of a randomized controlled trial in China. BMC Public Health 2015;15:210.

23. Ji CY. Working Group on Obesity in China. Report on childhood obesity in China (1)-body mass index reference for screening overweight and obesity in Chinese school-age children. Biomed Environ Sci 2005;18:390-400.

24. National High Blood Pressure Education Program Working Group on High Blood Pressure in Children and Adolescents. The fourth report on the diagnosis, evaluation, and treatment of high blood pressure in children and adolescents. Pediatrics 2004;114:555-76.

25. Gutin B. Child obesity can be reduced with vigorous activity rather than restriction of energy intake. Obesity 2008;16:2193-6.

26. Chen C, Lu F. The guidelines for prevention and control of overweight and obesity in Chinese adults. Biomedical \& Environmental Sciences Bes 2004;17 Suppl(Suppl:1-36.
27. Schellong K, Schulz S, Harder T, et al. Birth weight and long-term overweight risk: systematic review and a meta-analysis including 643,902 persons from 66 studies and 26 countries globally. PLoS One 2012;7:e47776.

28. Qiao Y, Ma J, Wang Y, et al. Birth weight and childhood obesity: a 12-country study. Int J Obes Suppl 2015;5(Suppl 2):S74-S79.

29. Ren J, Wu J, Ji M, et al. The effect of high birth weight on overweight and obesity in childhood and adolescence. A cohort study in China. Saudi Med J 2013;34:623-31.

30. Liu ZW, Zhang JT, Cai QY, et al. Birth weight is associated with placental fat mass- and obesity-associated gene expression and promoter methylation in a Chinese population. J Matern Fetal Neonatal Med 2016;29:106-11.

31. Singhal A, Wells J, Cole TJ, et al. Programming of lean body mass: a link between birth weight, obesity, and cardiovascular disease? Am J Clin Nutr 2003;77:726-30.

32. Hong J, Shi J, Qi L, et al. Genetic susceptibility, birth weight and obesity risk in young Chinese. Int J Obes 2013;37:673-7.

33. Kilpeläinen TO, den Hoed M, Ong KK, et al. Obesity-susceptibility loci have a limited influence on birth weight: a meta-analysis of up to 28,219 individuals. Am J Clin Nutr 2011;93:851-60.

34. Poston L, Caleyachetty R, Cnattingius S, et al. Preconceptional and maternal obesity: epidemiology and health consequences. Lancet Diabetes Endocrinol 2016;4:1025-36.

35. Marchi J, Berg M, Dencker A, et al. Risks associated with obesity in pregnancy, for the mother and baby: a systematic review of reviews. Obes Rev 2015;16:621-38.

36. Institute of Medicine. Weight Gain during Pregnancy: Reexamining the Guidelines. Washington (DC): National Academies Press (US), 2009.

37. Farzandipour M, Nabovati E, Anvari S, et al. Phone-based interventions to control gestational weight gain: a systematic review on features and effects. Inform Health Soc Care 2018;27:1-16 